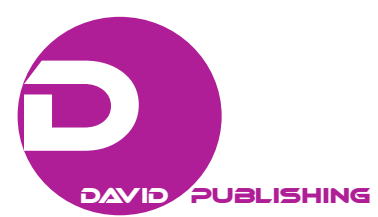

\title{
Innovation in Technology and Organization as a Factor in the Development of Agribusiness
}

\author{
Bojan Jokić, Sonja D. Radenković \\ College of Economics Peć-Leposavić, Leposavić, Kosovo \\ Bojana Jokić \\ Academy for Business Economy, Belgrade, Serbia
}

\begin{abstract}
The dynamism of the environmental factors determines the permanent relativization of the existing position of the company, which is why it is forced to constantly adjust its size and internal configuration to the requirements imposed by the development of social, technical, technological and market factors. In this way, the enterprise fulfils the social justification of its existence and functioning. The company can realize the aspiration to improve its position by any active influence on environmental factors by appropriate response to challenges and chances from the environment. As a result of this behaviour, the company comes to the process of its growth and development. Growth of the company is the process of increasing the size of the company and can manifest itself as an increase: the number of employees, strength and installed capacity, total income, market share, profits and the like. The process of growth of the company, as the inevitable consequence of its tendency to improve its position, necessarily leads to the diversification of the company's activities, changes in its organizational structure, and other adaptive changes.
\end{abstract}

Keywords: agribusiness, grownth, strategy, technology

\section{Introduction}

The growth and the development of the company are due to the tendency to adapt the company to changes in the market, technological and social requirements by certain changes in size, accumulation capability, and organizational structure. In this way, the company aims to provide long-term vitality in modern agribusiness conditions.

The company's growth and development process is performing simultaneously. Both processes are interconnected and conditioned, so it is difficult to distinguish them precisely. As a result, the growth and development of the company must be viewed together, taking into account their interaction and synergetic effects. Some authors link the growth to quantitative and development for qualitative changes in company performance. It certainly makes it easy to analyze these processes, although, on the other hand, it can give a distorted, or simplified picture of the complexity of the impact of these two processes.

Bojan Jokić, Ph.D., professor, College of Economics Peć-Leposavić, Dositeja Obradovića bb, Leposavić, Kosovo.

Sonja D. Radenković, Ph.D., professor, College of Economics Peć-Leposavić, Dositeja Obradovića bb, Leposavić, Kosovo.

Bojana Jokić, Ph.D., professor, Academy for Business Economy, Belgrade, Serbia.

Correspondence concerning this article should be addressed to Sonja D. Radenković, College of Economics Peć-Leposavić, Dositeja Obradovića bb, Leposavić 38218, Kosovo. 
Growth and development of the company are not the aim by themselves. The basic role of the process of growth and development is to train the company for the most efficient implementation of its socio-economic the mission. Given degree of socio-economic development is achieved by planned changes in the size, assortment, and organizational structure of the economic entity. The growth and development of an enterprise can be realized in two different forms that can manifest themselves as induced development and as an autonomous development.

Induced development implies a mere adjustment of the company to market changes, whereby the company hasn't influenced the market changes in any way. Such a passive response may be a consequence of the insufficient strength of the company in order to affect the market conditions, the slow the reaction of the company to market conditions, as well as the conscious rejection of the company from the action to the fear of premature reactions. The autonomous development of the enterprise implies the reaction of the company to market changes, as well as the induction of the given changes (Milisavljević \& Todorović, 1995). For example, it can be achieved by introducing innovations. In real world, it is difficult to distinguish the autonomous and induced growth and development of the company, since there are many transitional forms between these two extreme models. What model of development and to what extent it will be used depend on the specific conditions in which the company operates. As a result, there should be a tendency for the company to achieve its development passively, by adjusting to existing changes, as well as by active role in initiating these changes.

On the basis of the previous one, it can be said that the growth and development of an enterprise are necessary processes from the standpoint of fulfilling the justification of its existence and, therefore, they are also a necessary condition for its survival. The growth and development of the company are determined by the action of a large number of factors that emanate both from the environment and from the company itself. Therefore, when formulating its development policy and development strategy, the company has to pay particular attention to the analysis and assessment of the functioning of development factors, which will depend on the definition of its development strategy.

\section{Prerequisites for Preparation and Initiation of New Technologies}

During its agribusiness, the company makes a series of activities in order to maintain and improve its market position. Those activities arise as a result of the need to adapt the company to the requirements of the environment, primarily the market, and are manifested as changes: types and scope of activity, product range, organizational structure, and technical and technological basis. Given changes reflect the ability of the company to adapt and change according to the requirements of the environment and depending on its capabilities and the condition of its survival and improvement of its market position.

Enterprise development represents the process of its adaptation to changes and environmental requirements. In order for this adjustment process to be as efficient as possible, the company must determine the factors that influence its development, as well as the essential characteristics of these factors. Accordingly, the company adjusts its agribusiness with the requirements of the environment in accordance with its capabilities, needs, and set goals with a series of appropriate activities.

Since many factors influence the development of the company, it is very important to identify and define them according to the character of their operation. The significance of the delimitation of factors by the nature of their actions on the company's operations is reflected in the fact that one group of these factors can be challenging and, if they are accepted, the chances for development and prosperity of the company. The second 
group may include those factors which, if not properly respected, may pose a threat to the agribusiness of the company and, in the end, can lead to the cessation of its functioning. However, it is possible that one and the same factor has the role and chances and threats to the agribusiness of the company, depending on how it is accessed during the agribusiness process. Such is the case with the technological development which, if the company approaches it in a timely and appropriate manner, can contribute to achieving long-term competitive advantage and optimal agribusiness results. However, if the company neglects its technological development and the monitoring of modern technological tendencies in the area in which it operates, it will necessarily impair its competitive position and the cessation of agribusiness.

Factors of enterprise development can be defined as a set of all occurrences of economic and non-economic character which, individually or interactively, condition the development of economic entities. The goal of identifying and studying agribusiness factors is to enable management to direct the agribusiness of the company by taking advantage of opportunities and avoiding hazards hidden in the environment. In order to understand better the factors of enterprise development, their study and the use of their activities more appropriately, it is necessary to direct the analysis towards systematization and division according to certain criteria. Criteria for the classification of development factors may vary, depending on the purpose of the study. Thus, according to the company's ability to influence their operation, development factors can be divided into objective and subjective.

Objective factors of development are those phenomena on which the enterprise cannot influence its organizational measures (Todorović, 1997). All objective factors can be divided into three groups: natural, technical, and social. Since objective factors can not affect an enterprise, they must adapt. Depending on where they come from, all objective factors can be divided into internal and external. Internal objective factors include: financial potential, size of the company, structure of production and possibilities of its change, organic composition of capital, organizational structure of the company, etc. The external objective factors of development include: the market, the level of scientific-technical development, natural conditions, the social organization of production, institutional conditions and public opinion.

Subjective factors of development are the phenomena on which a company can influence its activities and direct them to stimulate its development. The subjective factors of enterprise development include the qualitative and quantitative potential of his working team, and above all, the managerial staff. Especially important elements of the creative potential of management forces stand out: the ability of executives to plan growth development, physical and psychological limitation of creative ability of company management in a given time period, experience and knowledge of managerial workers, elasticity of leadership supply in the short and long run, leadership inclination enterprise risk, an economic horizon of the disposable factor, the ability to procure, transmit, and utilize information, and the like.

\section{Importance of Technological Development for Acquiring Competitive Advantages of Company}

Technological and technological progress represents the process of introducing new technical and technological solutions into the process of social reproduction, thus achieving the development of productive forces as well as overall economic and social development. At present level of economic development, technical and technological progress is the dominant factor of this development and, it can be said, its basic condition. It follows that economic operators who are trying to maintain and improve their competitive position 
must systematically and continuously monitor and apply new technical and technological solutions in accordance with their capabilities and requirements of the environment. For, as the Latin proverb says: "Non progress est regredi"-Do not progress means to go down.

Technical-technological progress caused very rapid changes in the field of: materials, classical and new products, means of operation, technological procedures, communication. The new technical-technological revolution has also led to a new international division of labor in which developing countries have become the "industrial pendant" of the developed.

Intensified research, especially in the field of physical and molecular biology, accelerated technical progress especially in the field of microchip technology and biotechnology. Robots, computers, and sensors replaced production and contributed to improving product quality.

Modern technical and technological progress, as a set of very large and rapid changes in the field of technology and technology, opens wide possibilities for applying new achievements and linking up to now completely unrelated areas and activities (Senić, 2007). In this way, there are synergetic effects when "everything depends on everything", so that all the technologies and technological assumptions connect into a single system and work in harmony.

The scientific-technological revolution enables the introduction of automation and robotization of production, as well as the individualization of products and the establishment of a continuous relationship between the manufacturer and the user.

The company operates in a complex and changing environment where technology is only one of the elements of this environment, however, with a very stressed, often crucial, influence. In addition to technological, the environment also includes the elements of social, political, economic, and public spheres that are in the process of constant change and among which there are relations of mutual conditionality and dependence.

From all above mentioned, it can be concluded that the company exists and operates in a very turbulent environment. One of the most important, but also the most uncertain factors is just technical and technological progress, which in certain conditions can be a chance, and in the other ones the limitation of growth and development of the company. As a matter of fact, if the economic entity perceives and anticipates technological changes and, accordingly, adjusts its own organizational structure and scope of production, technical and technological progress for it will be a propulsive factor of development. However, any neglection, isolation, and avoidance of technical and technological changes will necessarily lead to a slowdown in the development, stagnation and, ultimately, the cessation of the functioning of the company.

\section{Developing Technology as Basis for Technological Transition}

The concept of life-cycle development of the product development assumes that the company participates in the design of a protected environment from the stage of conceptual development of the product or processes up to the recycling of the researched projected entity (Milisavljević \& Todorović, 1991). When developing and introducing new technologies, it is necessary to explore and appreciate a whole set of rules on industrial and overall economic development.

The application and development of new technologies at the same time should satisfy the demands of the different structures that make up the economic and social system, which presupposes defining a new strategy of technological management in enterprises. 
The existence of an enterprise in modern economic conditions depends on the ability of management to recognize on the basis of reliable forecasts and prognostic methods of the future buyers' structure. By identifying potential customers, the enterprise defines their future needs and defines ways to meet customer needs.

The strategic, leading position of the company, can be achieved through the introduction of new dominant technologies with the following characteristics: durability, elasticity, reduction in material and energy consumption, reduction of waste and damage, short maintenance time and continuous driveability.

A new product that needs to satisfy the interests of different structures comes as a result of two effects:

- Pull-market effect;

- Push - the effect of technology.

It is necessary to change the concurrent position of the company with the new technologies. The application of strategic technologies involves the preparation of an enterprise strategy that should encompass sub-management of the management, marketing, finance, research and development, production, procurement and human resources. These strategies get a feature of functional strategies.

The strategy of implementing the new technologies is part of the company's overall strategy. By introducing of applying the new technologies, the company becomes stronger at both local and globalized markets.

The product development policy and company development policy are equally important for the company's global policy.

Flexibility of manufacturing technologies creates objective possibilities for diversifying assortment of production and products, offering multi-generational products, and building multi-technology capabilities.

A wide range of products based on "soft" products enables the offer of new products to be adapted to the needs and demands of the market. This diversification involves the existence of a certain level of company's specialization in technological participation in the creation of new products.

Multi-purpose products are those that have such project technological characteristics that, depending on the scope of the application and the timing of the need for them, they can be offered to the market in the short term.

Multithreading capacities have the capacity to reconfigure, depending on the type of product being manufactured.

\section{Technological Development Using the Network and Tree Relevance}

The multidimensional "hyper-space" has the disadvantage that it is difficult to understand, and this means for use. Therefore, it is useful to indicate the introduction of networks and relevance trees that clearly show the emergence and flow of products or technology. Network representation may relate to the evolutionary development of technology, the mission network of a technological program that encompasses the state, the chosen policy for that state, the operations, and the specification of the base missions. Finding a critical path through a formed network requires the use of the PERT method.

The structure of activities in technology management can also be presented through the tree of the target or tree of relevance on which the lists of necessary prerequisites as well as alternative alternative solutions are established. This structure has the shape of a tree, at which two upstream levels we have the necessary prerequisites - sufficient alternatives for these conditions. And here we face the phenomenon of axiomatics where there is a relation between the functional requirements and the parameters of the design. 


\section{Formulation of Investment Strategy for the Technological Development of Company}

As previously mentioned, with technology as the most important development factor, the company can manage and transform from danger to its chance of success. Therefore, solving the problem of technological development requires a strategic approach (Twiss \& Goodbridge, 1989). Globally, the company's technology strategy can be defined as the long-term commitment of the company to the place and the role of technology in its agribusiness. As such, the technology strategy is an essential element of the overall strategy of the company and should include responses to three important issues:

- which technology companies need to develop?

- should it be necessary to achieve a technological leadership in these activities?

- what are the possibilities of selling technology?

Some authors define the technology strategy much broader, or as an aspect of the strategy of the company, which refers to the exploitation, development, and maintenance of the overall knowledge and skills of the company, in the longer period of time.

Modern agribusiness conditions are characterized by great variability and uncertainty.

Accordingly, the global company strategy, and the technology development strategy as an integral part of it, must constantly adapt to these changes. Actually, Continuous monitoring and analysis of current technological changes is a prerequisite for creating an appropriate basis for making strategic decisions (Todosijević, 2009). The reality of the database is more important if it is kept in mind that the decisions made at present have consequences only in the future. Consequently, decisions must not be made retroactively but proactively, which means that they must anticipate the conditions in which their effects will be revealed.

Changing agribusiness conditions also require that making strategic decisions must be preceded by a detailed analysis of the past agribusiness, an assessment of the current situation and the foreseeing of future developments in the domestic and international environment. By applying the formulation of its technology strategy, agribusinesses must set a balance between their capabilities and the requirements of the environment. Therefore, the same change in the environment can be generally advantageous for the agribusiness of the company, but only if the company responds to it in an adequate manner (Kurpick, 1981). However, the given advantage can be cancelled by the company's wrong actions and the chance can be turned into a threat to its agribusiness.

In accordance with the above, a set of agribusiness goals must make the base for forming a strategy for technological development. That means that the technological strategy must be consistent with the goals of the company and contribute to their gradual achievement. Any need to introduce new technology must be seen objectively in the long run. As a matter of fact, the following must be taken into account: the influence of objective factors, the existence of subjective constraints and their longevity, the availability of appropriate information, and the like.

The established technology development strategy of the company should be in accordance with:

- long-term goals of the company;

- the overall potential of the company;

- the environment of the company.

A timely assessment of the impact of technological changes, as well as the timely formulation of an adequate strategy for technological development, have a significant impact on the place, role, and perspectives of the company in its environment. 


\section{The Role of Technology Market in Formulating the Development Strategy}

At today's level of development of the world economy, technology is one of the most important factors. Technology causes and allows important strategic changes both at the level of the economy as a whole and at the enterprise level as the main economic entity (Kukoleča, Stavrić, Stojaković, \& Zdravković, 2009). More and more intensive scientific research leads to more and more technical progress, especially in areas such as: microelectronics, computing, production of new forms of energy and materials, genetic engineering and the like.

Starting from the above importance for economic and overall social development, technology becomes the subject of market exchange, that is, becomes a kind of commodity. In this sense, a special market of technology, or applicable knowledge, is being developed.

It can be said that technological changes are the basis of all changes in the company's agribusiness, with the intensity of their impact being different for individual industries and production areas.

It should be emphasized that the significance of technical progress and technological development for the survival and development of enterprises today is significantly different from the previous periods. The reasons for this are the following:

- old technologies have limited potential,

- new technologies are developed at a much higher rate,

- new agribusiness investments are based largely on new technologies,

- when purchasing products, quality plays a decisive role in relation to price,

- the life cycle of technology has a tendency to shorten,

- the product life cycle also has a tendency to shorten,

- technological development costs tend to increase participation in the cost of product cost,

- the relationship between profitability and new product value has a decisive influence on decision-making,

- the number of technological competences of the company has a tendency to increase.

For all this, it is very dangerous for the company to ignore technological changes. As a matter of fact, if the company does not follow properly and does not respect technological changes, it necessarily reduces its competitiveness, the deterioration of the market position, and the termination of agribusiness.

The reasons for such disinformation of the company in this sphere may be different, and most often are the following:

- non-investment in new technologies,

- investing in the wrong, i.e., obsolete or inadequate technologies,

- the seduction of the currently favorable position on the market and the endeavor to maintain the status quo,

- lack of material, financial and human resources for adequate use of the existing and timely introduction of new technology.

The company can manage technology as one of the most important development factors, and transform it from danger to its chance of success. In that sense, solving the problem of technological development requires a strategic approach. Technological strategy enterprises can be defined as a long-term commitment of the company to the place and role of technology in its agribusiness.

Technology has a very complex impact on the company's agribusiness. This complexity is manifested in many global aspects of agribusiness as well as in specific issues such as: what, where, and how it is produced 
and sold. Technological changes affect changing all segments of the reproduction cycle in the company. Those changes cause a series of organizational changes in the company itself, which are interconnected and conditioned.

The impact of technological changes varies depending on the economic sector (Novak \& Popović, 1996). In recent years, under the influence of technology development, there have been major changes in agribusiness, both national and international. Certain industries, such as electronics, pharmaceutical and petrochemical industries, etc., have made progress, while other industries, such as the steel industry, have stagnated and made their position even worse. The first group of branches is called technologically intensive branches and has become such thanks to the ability of its agribusiness entities to adequately monitor, apply, and develop new technology (Djokic, Arsic, \& Rakic, 2017).

Activities in the world market of technology are becoming more and more intense. That presents a major challenge for the old-age management of the company, which stems from the fact that technology is an important condition for acquiring and improving the market position of the company. In that context, the company can choose one of the possible variants of acquiring new technologies, such as own development or transfer from domestic and foreign sources of knowledge.

\section{Conclusion}

In the near future, a successful company will only be structured to give proper and constant attention to external and internal problems. Besides, the management structure will lead innovation. The quest for chances, opportunities, and problems will be institutionalized and will be continuously carried out. The internal production cycle will be oriented towards DR (development research), and production and marketing will be flexible and responsive to changes in the so-called mixture of product and market. The dynamics of technology is in the focus of interest of the modern company, because it is a vital resource for its competitiveness.

Considering the company's technological strategy begins with a global overview of the role place of technology in achieving the competitive advantage of the company. Technological strategies are integrally observed in the agribusiness strategy and in particular consider the touch points and key interactions among technology and other functions in the agribusiness system strategy. When it comes to companies in high technology, there are several strategic options: first to the market, the other to the market, late to the market and minimizing costs, market segmentation. Modern companies start from the need to establish an innovative organization, which is open at any moment to change and capable of absorbing the change as soon as possible in order to preserve vitality and competitiveness in the market.

It seeks to achieve a higher degree of flexibility and process technology from a standpoint, among others, the ability to generate multiple product life cycles within a flexible process technology. Beside the mentioned flexibility of new technologies, the organization's ability to offer a broader range of products is needed, to have better respond to changing demands on the market, and thus gain a significant advantage over the competition, also achieve greater technological diversification (Senić, 2007). This creates a higher degree of flexibility compared to the different programs that can be offered to the market. The technology portfolio analysis can provide valuable data on the status of individual technologies in the company in relation to the technological level and in relation to the needs of the market within different strategic agribusiness units.

The agribusiness strategy of the company is closely related to the technology strategy, and the analysis of the relationship between technological innovations of products and processes in enterprises is the starting point 
for determining the future directions of strategic engagement. The tendency towards achieving growth in profitability and competitive advantage in modern markets, with the advent of new information technology, undoubtedly means orientation towards the development of the possibility of offering a wider range and a greater variety of products and services.

\section{References}

Djokic, N., Arsic, Lj., \& Rakic, G. (2017). Effects of innovative activities as a successful development factor of the Republic of Serbia. In Proceedings of the International Conference Challenges of Sustainable Development-Economic and Social Aspects, Faculty of Economics, Prishtina-Kos. Mitrovica (pp. 433-445). ISBN 978-86-80127-85-9 UDC: 338.124.4(100).

Kukoleča, S., Stavrić, B., Stojaković, S., \& Zdravković, R. (2009). Economics and production organization: The techno-economic aspects of production. Belgrade, Serba: Savremena administracija.

Kurpick, H. (1981). Das Unternehmenswachstum als betriebswirtschaftliches problem. Berlin, Germany: Dunker \& Humbolt.

Milisavljević, M., \& Todorović, J. (1995). Planning and development policy of the enterprise. Belgrade, Serbia: Savremena administracija.

Milisavljević, M., \& Todorović, J. (1991). Strategy management. Belgrade, Serbia: Ekonomski fakultet.

Novak, M., \& Popović, Ž. (1996). Development policy. Zagreb, Croatia: Informator.

Senić, R. (2007). Managing of growth and enterprise development. Belgrade, Serbia: Savremena administracija.

Todorović, J. (1997). Concepts of the company's growth strategy. Belgrade, Serbia: Naučna knjiga.

Todosijević, R. (2009). Strategy management, Book 2, the methods and techniques for strategy management. Subotica, Serbia: School of Economy.

Twiss, B., \& Goodbridge, M. (1989). Managing technology for vompetitive advantage. London, UK: Pitman. 